\title{
Unrecognized Heart Failure and Chronic Obstructive Pulmonary Disease (COPD) in Frail Elderly Detected Through a Near-Home Targeted Screening Strategy
}

\author{
Yvonne van Mourik, MD, Loes C. M. Bertens, PhD, Maarten J. M. Cramer, MD, PhD, \\ Jan-Willem J. Lammers, MD, PhD, Johannes B. Reitsma, MD, PhD, \\ Karel G. M. Moons, PhD, Arno W. Hoes, MD, PhD, and Frans H. Rutten, MD, PhD
}

Background: Reduced exercise tolerance and dyspnea are common in older people, and heart failure (HF) and chronic obstructive pulmonary disease (COPD) are the main causes. We want to determine the prevalence of previously unrecognized HF, COPD, and other chronic diseases in frail older people using a nearhome targeted screening strategy.

Methods: Community-dwelling frail persons aged $\geq 65$ years underwent a 2 -step screening strategy. First, they received a questionnaire inquiring about dyspnea and exercise tolerance. Those with exercise intolerance and/or dyspnea were invited to visit their primary care physician's office for a screening program, including medical history taking, physical examination, blood tests, electrocardiography, spirometry, and echocardiography. The final diagnosis of every patient was determined by a panel consisting of 3 physicians.

Results:tk;2 of the 570 elderly who filled out the questionnaire, 395 (69\%) had reduced exercise tolerance or dyspnea. of these, 389 underwent the screening program: $127(33.5 \%, 95 \%$ confidence interval, 28.9-38.4\%) were newly diagnosed with HF (mainly HF with a preserved ejection fraction $[23.5 \%]$ ), and previously unrecognized COPD was detected in $16.8 \%$ (95\% confidence interval, $13.4-$ $20.9 \%)$. In total, 165 patients $(43.9 \%)$ received a new diagnosis of either HF, COPD, or both. Other new diagnoses (in $32.7 \%$ of the screening program patients) included atrial fibrillation $(1.8 \%)$, valvular disease (21.4\%), (persisting) asthma (3.1\%), anemia (12.7\%), and thyroid disease (0.6\%). No clear explanation for the complaints of 47 patients (12.2\%) was found using our strategy.

Conclusion: Unrecognized chronic diseases might be detected in community-dwelling frail elderly using a near-home screening strategy that is simple to implement. It remains to be proven, however, whether optimizing treatment of the newly detected diagnoses in this fragile population with multimorbidities and polypharmacy improves quality of life and reduces morbidity and mortality. ( $\mathrm{J}$ Am Board Fam Med 2014;27:811-821.)

Keywords: Cardiovascular Abnormalities, COPD, Dyspnea, Exercise Tolerance, Frail Elderly, Heart Failure, Respiratory Tract Diseases

Reduced exercise tolerance and dyspnea are common in the elderly; varying prevalence estimates range from $20 \%$ to $60 \% .{ }^{1-3}$ Heart failure (HF) and

This article was externally peer reviewed.

Submitted 30 January 2014; revised 29 June 2014; accepted 1 July 2014 .

From the Julius Center for Health Sciences and Primary care (YvM, JBR, KGMM, AWH, FHR), the Department of Cardiology, Heart Lung Center (MJMC), and the Department of Respiratory Medicine (J-WJL), University Medical Center Utrecht, Utrecht, the Netherlands. chronic obstructive pulmonary disease (COPD) are the main causes for these complaints and are highly prevalent in the general elderly population. ${ }^{2}$ Prev-

Funding: The study was conducted as part of the Dutch National Care for the Elderly Program (ZonMw-NPO) and was supported by a research grant from the Netherlands Organization for Health Research and Development (ZonMw grant no. 311040302).

Conflict of interest: none declared.

Corresponding author: Yvonne van Mourik, MD, Julius Center for Health Sciences and Primary care, University Medical Center Utrecht, Stratenum 6.131, PO Box 85500, 3508 AB Utrecht, The Netherlands (E-mail: Y.vanMourik@umcutrecht.nl). 
alence of COPD varies between $4 \%$ and $16 \%$ and that of $\mathrm{HF}$ between $3 \%$ and $13 \%$-these proportions are suspected to be even higher in frail elderly. ${ }^{4,5}$

Other diseases or precipitating factors that may simultaneously cause these symptoms should also be considered, such as anemia, atrial fibrillation, valvular disease, (persisting) asthma, thyroid disorder, and obesity. Importantly, both patients and physicians often do not seem to consider the development of another disease causing symptoms and signs similar to the patient's known condition. This has been exhibited extensively by previous studies showing very high prevalence rates of unknown HF in patients with COPD.,

$\mathrm{HF}$ and COPD may be difficult to disentangle because of overlap in signs and symptoms, and additional investigations, such as echocardiography and spirometry, are required for an adequate diagnosis. ${ }^{8-10}$ Access to echocardiography and, to a lesser extent, spirometry is limited in the primary care setting in European countries, a barrier that is even larger because of difficulties among the frail elderly in visiting the outpatient clinic of a hospital. $^{7,11-13}$

The aim of our study was to determine the prevalence of previously unrecognized $\mathrm{HF}, \mathrm{COPD}$, and other chronic diseases (eg, anemia, atrial fibrillation, valvular disease, asthma, thyroid disorders) in frail elderly using a near-home, targeted, 2-step screening strategy, including a questionnaire and a screening program at the primary care physician's (PCP) office.

\section{Methods}

\section{Study Population}

The study population was derived from a cluster randomized trial (www.clinicaltrials.gov identifier NCT01148719). ${ }^{14}$ Eight group primary care practices from the catchment area of the "Network Utrecht Care for Elderly" (NUZO) were included in the screening strategy. In the Netherlands, all citizens are registered with a PCP, irrespective of (co)treatment by a specialist. This includes patients living in a home for the elderly but excludes those living in a nursing home or hospice.

Frail patients $\geq 65$ years old were identified from the electronic medical files of the participating PCPs. Frailty is a clinical state in which there is an increase in an individual's vulnerability for devel- oping increased dependence and/or mortality. ${ }^{15}$ Frailty can occur as the result of a range of diseases and medical conditions. Numerous instruments used to score frailty, mainly based on physical and physiologic deficits, exist, but a single definition is lacking. ${ }^{15,16}$ Our definition of frail was practically operationalized as having $\geq 3$ chronic or vitalitythreatening diseases (such as ischemic heart disease) and/or using $\geq 5$ prescribed drugs daily during the past year. ${ }^{17}$ These variables could be extracted easily from the electronic medical file. Patients were excluded if they (1) already had a dual diagnosis of HF and COPD (both adequately established), including echocardiography or spirometry, respectively, according to the current clinical guidelines; (2) were unable to travel to the PCP's office; or (3) had severe cognitive problems. $\mathrm{Pa}$ tients willing to participate filled out a questionnaire, which included the Medical Research Council (MRC) Dyspnea Scale ${ }^{18}$ and questions about reduced exercise tolerance, that was sent by mail (the first step of the screening strategy) (see Appendix 1). Those who scored positive on the reduced exercise tolerance questionnaire or had a score $\geq 2$ on the MRC dyspnea scale were invited for the second step of the screening strategy at their PCP's office.

The study was approved by the medical ethics committee of the University Medical Center Utrecht, the Netherlands, and all participants gave written informed consent. Participant recruitment started in June 2010 and ended in January 2012.

\section{Near-Home Targeted Screening Program}

The screening strategy consisted of the following components: (1) standardized medical history taking and physical examination, (2) blood tests, (3) electrocardiography (ECG), (4) spirometry, and (5) echocardiography with a mobile device.

Data on comorbidities and drug use were obtained from the electronic medical file at the PCP's office. Current drug use was confirmed by checking the patients' medication containers.

Blood tests consisted of measurements of hemoglobin concentration, renal function (estimated glomerular filtration rate [eGFR] based on the Modification of Diet in Renal Disease study group equation), ${ }^{19}$ nonfasting glucose concentration, and concentrations of highly sensitive C-reactive protein, thyroid-stimulating hormone (and free thyroxin 4 in the case of values that were too low or 
too high), and N-terminal pro-B-type natriuretic peptide.

A standard 12-lead ECG was recorded and classified according to the Minnesota coding criteria by a single cardiologist. ${ }^{20,21}$

Pulmonary function tests consisted of spirometric measurements and were performed with a SpiroPerfect spirometer (Welch Allyn, Skaneateles Falls, NY). Forced vital capacity (FVC) and forced expiratory volume in 1 second $\left(\mathrm{FEV}_{1}\right)$ were measured before and 30 minutes after administration of ipratropium bromide via an inhalation chamber. ${ }^{22}$

Echocardiograms were performed with a mobile ultrasound machine (Vivid-I; General Electric, Milwaukee, WI) by trained and experienced cardiosonographers. Images and measurements, including tissue Doppler, were interpreted by an experienced cardiologist and reviewed by the cardiologist who was involved in the expert panel.

Blood could not be collected in 5 patients (1.3\%). The ECG and spirometry were not interpretable for technical reasons in 1 patient and 3 patients, respectively. Interpretable echocardiograms were available for 375 patients (96.4\%).

All measurements were performed in a nearhome setting at the PCP's office by trained technicians and sonographers from a locally operating PCP laboratory (Saltro, Utrecht, the Netherlands). After the screening program, the participant's PCP received all results and was advised to initiate targeted interventions and/or adjust current treatments, according to the recommendations of (inter)national clinical guidelines.

\section{Final Diagnoses}

The final diagnoses were made during consensus meetings by a panel consisting of a PCP, pulmonologist, and cardiologist and based on all available results from the screening program plus the response to treatment during the 6 months of follow-up. ${ }^{23}$ For diagnoses lacking a reference standard, such as HF, a consensus diagnosis based on expert opinion using all available diagnostic information was advocated. ${ }^{24}$ Diagnoses of HF, COPD, and other possible disorders that could explain the complaints were classified as present, absent, or, in case of doubt, "possible."

For the diagnosis of HF, the panel applied the diagnostic criteria of the European Society for Cardiology. HF was considered present if symptoms and signs suggesting HF were present in combina- tion with ventricular dysfunction on echocardiography at rest. ${ }^{8,25}$

Patients with HF were further classified as having $\mathrm{HF}$ with reduced ejection fraction (REF), HF with preserved ejection fraction (PEF), and isolated right-sided HF. "Systolic" dysfunction necessary for HF with REF was considered present if the left ventricular ejection fraction (LVEF) was $\leq 45 \%$ on echocardiography. "Diastolic" dysfunction, required for the diagnosis $\mathrm{HF}$ with $\mathrm{PEF}$, was considered present when LVEF was $\geq 45 \%$ and the following echocardiographic abnormalities were present: abnormal left ventricular relaxation or diastolic stiffness and structural abnormalities (left atrial enlargement or left ventricular hypertrophy). "Isolated" right-sided dysfunction was defined as an increased pulmonary artery pressure (calculated systolic pulmonary artery pressure $>40 \mathrm{~mm} \mathrm{Hg}$ ), when LVEF was $\geq 45 \%$, and in the absence of evident diastolic dysfunction.

The presence of COPD was based on the patient's history (ie, coughing, wheezing, phlegm production, inhalation allergy, and/or bronchial hyperreactivity), a positive history of smoking, and obstruction after dilation on spirometry. Obstruction was defined as a reduced ratio $(<0.70)$ of the $\mathrm{FEV}_{1}$ and FVC. Severity of COPD was graded according to the Global Initiative for Chronic Obstructive Lung Disease criteria in classes I to IV. ${ }^{26}$

For the diagnosis of (persisting) asthma, symptoms of wheezing plus a history of allergy or bronchial hyperreactivity was needed in combination with an increase of $>12 \%$ of the $\mathrm{FEV}_{1}$ value, or $\geq 200 \mathrm{~mL}$ in the case of smaller lung volume, from before to after dilatory measurement. ${ }^{27}$ The diagnosis of pulmonary restriction was based on a value of $<80 \%$ of predicted FVC after dilation in the absence of a diagnosis of COPD. ${ }^{27}$

Anemia was classified according to the World Health Organization criteria and was considered present if hemoglobin concentration was $<8.0$ $\mathrm{mmol} / \mathrm{L}(<13 \mathrm{~g} / \mathrm{dL})$ in men and $<7.4 \mathrm{mmol} / \mathrm{L}$ $(<12 \mathrm{~g} / \mathrm{dL})$ in women. Renal dysfunction was considered present if the eGFR was $<60 \mathrm{~mL} / \mathrm{min} / 1.73$ $\mathrm{m}^{2}{ }^{19}$ Thyroid disease was divided into hypothyroidism and hyperthyroidism. Hypothyroidism was considered present if the thyroid-stimulating hormone concentration was $>5.5 \mathrm{mu} / \mathrm{L}$ and that of free thyroxin 4 was $<11 \mathrm{pmol} / \mathrm{L}$. Hyperthyroidism was considered present if the thyroid-stimulating 
hormone concentration was $<0.35 \mathrm{mu} / \mathrm{L}$ and that of free thyroxin 4 was $>23 \mathrm{pmol} / \mathrm{L}$.

Blinded to their original classification, the panel reevaluated the diagnosis of a random sample of $10 \%$ of the patients $(n=40)$ to determine the reproducibility of their diagnoses. To minimize the chance of recall, the time interval between the 2 assessments was $\geq 1.5$ months. In 3 cases with a diagnosis of HF (presence or absence of HF with $\mathrm{PEF}$ ) and in 6 cases with a diagnosis of COPD, the diagnosis upon reevaluation did not correspond to the original diagnosis of the panel $(\kappa=0.74)$.

\section{Data Analysis}

The original diagnoses of the panel were used in our analyses, and diagnoses were dichotomized, considering a "possible" diagnosis as "absent." The prevalence of previously unrecognized $\mathrm{HF}$, COPD, and other chronic diseases was calculated as a proportion with $95 \%$ confidence intervals (CIs) using the method of Wilson. ${ }^{28}$ Data were analyzed using the SPSS software (version 20.0 for Windows; SPSS Inc., Chicago, IL).

\section{Results}

Of the 5369 elderly that were evaluated, 1855 (34.6\%) fulfilled the criteria for "frailty." Of these, $44(2.4 \%)$ had an already established dual diagnosis of $\mathrm{HF}$ and COPD and thus were excluded from the study (Figure 1). In total, 462 elderly did not respond to the invitation and 779 elderly were not willing to participate in the 2-step screening program. These nonresponders were, on average, 1.5 years older (76.7 vs 75.1 years; $P<.0001$ ), less often men ( $41.4 \%$ vs $50.9 \% ; P<.0001)$, and more often had a history of diabetes mellitus $(35.3 \%$ vs $30.4 \% ; P=.04)$ and cancer $(7.9 \%$ vs $4.9 \% ; P=$ $.03)$ than the participants. Prevalence of other comorbidities, including hypertension and ischemic heart disease, was similar. Of the frail elderly willing to participate, 395 (69.3\%) had dyspnea or reduced exercise tolerance. Six patients withdrew after signing informed consent. The mean age of the participants who visited their PCP's office for the screening investigations was 75.5 years (standard deviation, 6.1 years), and $45 \%$ were men (Table 1).

Table 2 presents the newly detected diagnoses. In the screening strategy, 525 new diagnoses were detected in 297 patients. Age- and sex-specific
Figure 1. Flow chart of inclusion. *“Other” includes cognitive problems (such as dementia) and inability to travel to the primary care physician's office.

${ }^{\dagger}$ Nonresponse after 2 written invitations were sent. COPD, chronic obstructive pulmonary disease; HF, heart failure; ECG, electrocardiogram.

\begin{tabular}{|c|}
\hline $\begin{array}{c}8 \text { general practices } \\
n=5369 \text { patients } 65 \text { years or older }\end{array}$ \\
\hline $\begin{array}{l}\text { Excluded: } \\
3267 \text { were not frail } \\
44 \text { dual diagnoses of COPD and } \mathrm{HF} \\
247 \text { other reasons }\end{array}$ \\
\hline $\begin{array}{l}1811 \text { frail elderly invited to fill out the dyspnea } \\
\text { and exercise tolerance questionnaires }\end{array}$ \\
\hline $\begin{array}{l}\text { Excluded: } \\
779 \text { not willing to participate } \\
462 \text { non-responders }\end{array}$ \\
\hline $\begin{array}{l}570 \text { filled out the dyspnea and exercise } \\
\text { tolerance questionnaires }\end{array}$ \\
\hline $\begin{array}{l}\text { Excluded: } \\
175 \text { no or insufficient scores on dyspnea } \\
\text { or exercise tolerance }\end{array}$ \\
\hline $\begin{array}{l}395 \text { frail elderly with a reduced exercise } \\
\text { tolerance and/or exercise induced dyspnea }\end{array}$ \\
\hline 6 withdrew \\
\hline $\begin{array}{l}\text { History taking and physical exam } \\
\text { Blood tests, ECG and spirometry } \\
\qquad n=389\end{array}$ \\
\hline $\begin{array}{l}\text { Echocardiography } \\
\qquad n=375\end{array}$ \\
\hline
\end{tabular}

prevalences of $\mathrm{HF}$ and COPD are presented in Figure 2.

HF was newly diagnosed in 127 patients (33.5\%; 95\% CI, $28.9-38.4 \%) ; 28.3 \%$ of these had HF with REF, $70.1 \%$ had HF with PEF, and $1.6 \%$ had isolated right-sided HF. Clinically relevant valvular disease was detected in $21.4 \%$ and atrial fibrillation in $1.8 \%$ of participants. At least one of these cardiac diseases was detected during screening in 168 (44.1\%) patients.

A new diagnosis of COPD was established in 65 patients (16.8\%; 95\% CI, 13.4-20.9\%). Persisting asthma was newly diagnosed in 12 patients $(3.1 \%)$ and pulmonary restriction in 9 patients $(2.3 \%)$. In 
Table 1. Demographic and Baseline Characteristics of 389 Frail Elderly With Dyspnea and/or Reduced Exercise Tolerance

\begin{tabular}{|c|c|}
\hline Age (years) & $75.5 \pm 6.1$ \\
\hline Male sex & $174(44.7)$ \\
\hline $\mathrm{BMI}\left(\mathrm{kg} / \mathrm{m}^{2}\right)$ & $28.2 \pm 4.4$ \\
\hline Heart rate/minute & $69 \pm 11$ \\
\hline Respiratory rate per minute & $15 \pm 3$ \\
\hline \multicolumn{2}{|l|}{ Blood pressure $(\mathrm{mm} \mathrm{Hg})$} \\
\hline Systolic & $139 \pm 18$ \\
\hline Diastolic & $76 \pm 9$ \\
\hline Smoking & $138(35.5)$ \\
\hline \multicolumn{2}{|l|}{ Never } \\
\hline Former & $214(55.0)$ \\
\hline Current & $37(9.5)$ \\
\hline \multicolumn{2}{|l|}{ Medical history* } \\
\hline Comorbidities (number), median (IQR) & $4(3-4)$ \\
\hline Heart failure & $22(5.7)$ \\
\hline COPD & $67(17.2)$ \\
\hline Asthma (persistent) & $36(9.3)$ \\
\hline Anemia & $14(3.6)$ \\
\hline Renal dysfunction & $12(3.1)$ \\
\hline Thyroid dysfunction & $34(8.7)$ \\
\hline Ischemic heart disease $^{\dagger}$ & $125(32.1)$ \\
\hline Valvular disease & $23(5.9)$ \\
\hline Cardiac rhythm disorders ${ }^{\ddagger}$ & $54(13.9)$ \\
\hline Hypertension & $316(81.2)$ \\
\hline Diabetes mellitus & $135(34.7)$ \\
\hline Stroke or TIA & $44(11.3)$ \\
\hline \multicolumn{2}{|l|}{ Symptoms } \\
\hline Orthopnea ${ }^{\S}$ & $39(10.0)$ \\
\hline Ankle swelling & $105(27.0)$ \\
\hline Nocturia ( $\geq 2$ times a night) & $199(51.2)$ \\
\hline Loss of appetite & $33(8.5)$ \\
\hline Chest pain suggestive for angina pectoris & $32(8.2)$ \\
\hline Palpitations & $109(28.0)$ \\
\hline Cough ( $>3$ months a year) & $66(17.0)$ \\
\hline Wheezing & $104(26.7)$ \\
\hline Inhalation allergy & $79(20.3)$ \\
\hline Bronchial hyperreactivity & $76(19.5)$ \\
\hline Medications, median (IQR) ${ }^{\|}$ & $5(4-7)$ \\
\hline Diuretics & $212(54.5)$ \\
\hline Spironolactone & $18(4.6)$ \\
\hline$\beta$-Blockers & $187(48.1)$ \\
\hline ACEIs/ARBs & $239(61.4)$ \\
\hline Cholesterol-lowering drugs & $232(59.6)$ \\
\hline Inhaled long-acting $\beta 2$-agonists & $60(15.4)$ \\
\hline
\end{tabular}

Continued
Table 1. Continued

$\begin{array}{ll}\text { Inhaled anticholinergics } & 56(14.4) \\ \text { Inhaled corticosteroids } & 73(18.8)\end{array}$

Data are mean \pm standard deviation or number (\%) unless otherwise indicated.

*Comorbidities were based on the primary care physician's electronic medical record; actual medication use from pharmacy records was added to the diagnosis of anemia, thyroid dysfunction, and diabetes mellitus; for hypertension, the electronic medical record was extended with self-reported hypertension.

${ }^{\dagger}$ Ischemic heart disease included prior myocardial infarction, angina pectoris, coronary artery bypass grafting, and percutaneous coronary intervention.

${ }^{\ddagger}$ Cardiac rhythm disorders included atrial fibrillation and pacemakers.

${ }^{\$}$ Orthopnea included paroxysmal nocturnal dyspnea.

"Based on actual medication use (pharmacy records); 2 instances of missing data on orthopnea and one on loss of appetite.

ACEI, angiotensin-converting enzyme inhibitor; ARB, angiotensin receptor blocker; BMI, body mass index; COPD, chronic obstructive pulmonary disease; IQR, interquartile range; TIA, transient ischemic attack.

79 patients (20.5\%), one or more of these pulmonary diseases was established at the screening.

Anemia was newly detected in $12.7 \%$ of patients and renal dysfunction (eGFR $<60 \mathrm{~mL} / \mathrm{min} / 1.73$ $\mathrm{m}^{2}$ ) in $25.0 \%$. Newly detected hypertension $(0.8 \%)$, diabetes mellitus $(0.8 \%)$, and thyroid disease $(0.5 \%)$ were infrequent.

The screening program at the PCP's office yielded an underlying cause for dyspnea or reduced exercise tolerance in $76.6 \%$ of the participants (95\% CI, 72.1-80.5\%). Possible explanations for the complaints in $11.2 \%$ of the participants-other than the diseases presented above-included (severe) obesity in $6.0 \%$, angina pectoris in $4.7 \%$, and peripheral artery disease in $1.1 \%$. According to the panel, the screening investigations did not reveal any explanation for the complaints in 47 participants $(12.2 \%)$.

\section{Discussion}

In our 2-step, near-home screening strategy among community-dwelling frail elderly, 69\% of the elderly had complaints of dyspnea or reduced exercise tolerance. Among these, screening investigations at their PCP's office established clinically relevant diagnoses in $77 \%$. In particular, Previously unrecognized HF and COPD were detected in many patients (34\% and $17 \%$, respectively). For $\mathrm{HF}$, this means a 3 times higher prevalence than can be expected in the general elderly population 
Table 2. New and "New Plus Already Known" Diagnoses* in 389 Frail Elderly With Dyspnea and/or Reduced Exercise Tolerance

\begin{tabular}{|c|c|c|}
\hline Diagnosed Conditions & New Diagnoses ${ }^{\dagger}$ & New Plus Already Known Diagnoses \\
\hline \multicolumn{3}{|l|}{ Cardiac diseases } \\
\hline Heart failure & $127(33.5)$ & $145(38.3)$ \\
\hline With reduced ejection fraction & $36(9.5)$ & $46(12.1)$ \\
\hline With preserved ejection fraction & $89(23.5)$ & $97(25.6)$ \\
\hline Isolated right-sided & $2(0.5)$ & $2(0.5)$ \\
\hline Left ventricular dysfunction ${ }^{\ddagger}$ & $81(34.6)$ & $\mathrm{X}$ \\
\hline Systolic & $3(1.3)$ & $\mathrm{X}$ \\
\hline Diastolic & $78(33.3)$ & $\mathrm{X}$ \\
\hline Atrial fibrillation & $7(1.8)$ & $44(11.3)$ \\
\hline Valvular disease $\mathrm{S}^{\S}$ & $81(21.4)$ & $93(24.6)$ \\
\hline Aortic regurgitation ( $\geq$ grade $2 / 4$ ) & $10(2.6)$ & $14(3.7)$ \\
\hline Aortic stenosis (moderate to severe) & $14(3.7)$ & $16(4.2)$ \\
\hline Mitral regurgitation ( $\geq$ grade $2 / 4$ ) & $67(17.7)$ & $74(19.6)$ \\
\hline \multicolumn{3}{|l|}{ Pulmonary diseases } \\
\hline COPD & $65(16.8)$ & $134(34.7)$ \\
\hline GOLD I & $31(8.2)$ & $53(14.0)$ \\
\hline GOLD II & $28(7.4)$ & $59(15.6)$ \\
\hline GOLD III & $3(0.8)$ & $11(2.9)$ \\
\hline GOLD IV & $0(0)$ & $0(0)$ \\
\hline Persisting asthma & $12(3.1)$ & $39(10.1)$ \\
\hline Restriction & $9(2.3)$ & $X$ \\
\hline \multicolumn{3}{|l|}{ Other diseases } \\
\hline Hypertension & $3(0.8)$ & $319(82.0)$ \\
\hline Diabetes mellitus & $3(0.8)$ & $138(35.5)$ \\
\hline Anemia & $49(12.7)$ & $63(16.3)$ \\
\hline Hyperthyroidism & $1(0.3)$ & $16(4.2)$ \\
\hline Hypothyroidism & $1(0.3)$ & $20(5.2)$ \\
\hline Renal dysfunction $\left(\mathrm{mL} / \mathrm{min} / 1.73 \mathrm{~m}^{2}\right)$ & $86(22.2)$ & $97(25.0)$ \\
\hline $30-60$ & $85(21.9)$ & $96(24.7)$ \\
\hline$<30$ & $1(0.3)$ & $1(0.3)$ \\
\hline
\end{tabular}

Data are number (\%).

*Patients could have more than one diagnosis.

${ }^{\dagger}$ There were 525 new diagnoses detected in 297 patients: 148 had 1, 94 had 2, 38 had 3, 11 had 4, 5 had 5, and 1 had 6. Because of an incomplete screening strategy or a nonassessable test, there were 10 instances of missing data on heart failure and dysfunction, 11 on valvular disease, 1 on atrial fibrillation, 3 on COPD, 11 on GOLD classification, 4 on asthma en restriction, 3 on anemia, and 4 on hypo- and hyperthyroidism.

${ }^{\ddagger}$ Left ventricular dysfunction without signs or symptoms of heart failure.

${ }^{\S}$ Patients could have more than one valve disorder.

COPD, chronic obstructive pulmonary disease; GOLD, Global Inititative for Chronic Obstructive Lung Disease; X = no such diagnosis in the electronic medical file at the primary care physician's office.

$\geq 65$ years old. ${ }^{5,9}$ Also, consistent with previous studies, prevalence estimates increased with age, and men were more affected than women. Men also had more major risk factors than women. ${ }^{4,5}$ Thus, our study confirms the underdiagnosis of both diseases in the elderly, as was shown by previous studies separately assessing these diseases. ${ }^{7,11-13}$ We also showed that these frail elderly, with multimorbidities, polypharmacy, and complaints of dyspnea, still have a substantial number of remaining undetected diseases, especially HF and COPD. These outcomes are applicable to $25 \%$ of all persons $\geq 65$ years old. This substantial underdiagnosis of important chronic diseases seems at least partly explained by both patients and physicians who attribute (increasing) dyspnea and exercise intolerance to the previously diagnosed disease(s). ${ }^{12,13}$ 
Figure 2. Age- and sex-specific prevalence of heart failure (HF) (A) and chronic obstructive pulmonary disease (COPD) (B). Total prevalence included new plus already known diagnoses.
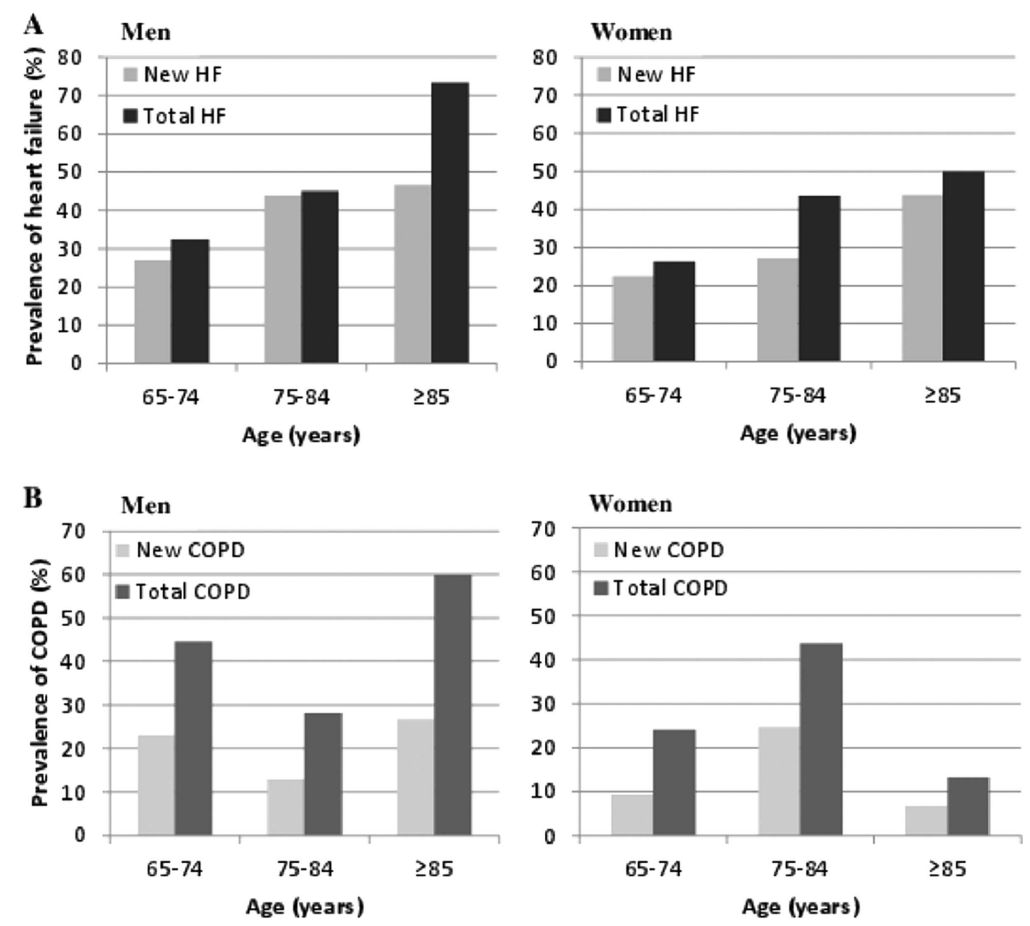

In addition, dyspnea and reduced exercise tolerance are not always perceived as important symptoms; deconditioning because of aging often is considered as the explanation. Reevaluating these complaints, however, as we did in our study, does imply a considerable effort; as many as $69 \%$ of all frail elderly had at least one of these complaints. The prevalence of dyspnea (MRC Dyspnea Scale score $\geq 2$ ) in our community-dwelling frail elderly $\geq 65$ years old $(60.8 \%)$ was substantially higher than that observed in an earlier study of the elderly population at large $(37 \%){ }^{29}$

The screening investigations in our study were relatively easy to perform (with the exception of the portable echocardiography), and the patient burden was limited. All investigations were performed in or nearby the PCP's office, in the vicinity of the participants' homes. As a consequence, implementing our 2-step screening strategy in other countries with a primary-care based health care system seems feasible, albeit that the quality of the measurements performed is high and PCP's are capable of interpreting the results.

Although most primary care practices in Western European countries nowadays have spirometry and often electrocardiography available, they lack easy access to echocardiography. This could possi-

bly be the main reason for the even higher detection rates of new HF than new COPD. Our study is in line with previous studies that showed that better access to echocardiography in primary care facilities will increase the detection rate of $\mathrm{HF}$ in the elderly and thus the quality of life and prognosis of these patients.

With our screening strategy, we focused on diseases that are common, easily detectable, and can be treated with evidence-based drugs that have a potential beneficial effect on prognosis and quality of life, although this effect is not that evident for cases with $\mathrm{HF}$ with $\mathrm{PEF}^{30}$ The risk of negative drug interactions and adverse effects in these patients, who often also have some degree of renal failure, need to carefully be considered. Thus, optimal, high-dose drug use according to guidelines is not always possible or adequate in these patients.

In view of the lack of evidence on the effects of targeted interventions in these elderly patients with newly detected diagnoses, randomized comparison assessing whether such interventions indeed improved prognosis should be available before a screening strategy such as ours can be implemented. Such an evaluation-the TREE (Triage of Reduced Exercise Tolerance in Frail Elderly) study—is currently underway. ${ }^{14}$ 


\section{Comparison With Other Studies}

Three previous studies screened adult patients with dyspnea for underlying causes, but these were conducted in a hospital outpatient setting and not in primary care. ${ }^{29,31,32}$ Two separate studies by Nielsen et $\mathrm{al}^{31,32}$ in Denmark found newly detected $\mathrm{HF}$ in $27 \%$ and $23 \%$ and new COPD in $32 \%$ and $48 \%$ of cases and no underlying reasons in $15 \%$ and $18 \%$ of cases, respectively. Pedersen et $\mathrm{al}^{29}$ considered cardiac and/or pulmonary diseases present in $69 \%$ of patients referred to the outpatient clinic for dyspnea (median age, 71.5 years; $31 \%$ men), classifying $21 \%$ with a new diagnosis of heart disease and $53 \%$ with pulmonary disease. In our study, the number of patients with newly detected heart disease (44\%) was much higher than in these earlier studies. Except for differences in patients' characteristics, differences in the classification of diastolic dysfunction with echocardiography and thus the diagnosis of HF with PEF could have at least partly created this difference. Importantly, we applied a composite of echocardiographic diastolic abnormalities, including tissue Doppler measurements of the left ventricular wall, as advocated by the most recent guidelines. $8,25,33,34$

\section{Strengths and Limitations}

A major strength of our study was that all investigations were performed in every patient, thus preventing workup bias (or verification bias). Another strength is that all investigations were done near the patients' homes, which certainly had a positive impact on the participation rate of these frail elderly, a patient population seldom included in large randomized trials. We did not assess all possible comorbidities or medications in Table 1 . We preferred to focus on those diseases that potentially could be related to dyspnea or reduced exercise tolerance.

In 14 patients (3.6\%), echocardiography could not be performed, most often because the patients' physical conditions made it impossible for them to visit their PCP's office. It is possible that not every patient adequately stopped his or her inhaled pulmonary drugs as instructed on the day of the spirometry. This might have negatively influenced the diagnosis, especially that of asthma. We performed only spirometry because this is the key investigation in primary care for diagnosing COPD and asthma. Not applying other pulmonary function tests could have led to some misclassification, es- pecially of those with a $\mathrm{FEV}_{1} / \mathrm{FVC}$ around the 0.70 cutoff point. Importantly, participants were in a stable condition, and thus the risk that pulmonary congestion due to $\mathrm{HF}$ that would reduce the $\mathrm{FEV}_{1}$ value more than the FVC value is unlikely. In general, in stable patients with $\mathrm{HF}$, both the $\mathrm{FEV}_{1}$ and FVC were reduced by $10 \%$ to $20 \%$, but because both values were affected, the ratio is not. ${ }^{35,36}$ Finally, our screening strategy did not include exercise testing or other investigations to detect cardiac ischemia. As a result, patients with dyspnea caused by cardiac ischemia may not be adequately detected by our screening strategy.

Because we had a $69 \%$ nonresponse rate, selection bias of participants could have occurred. Nonresponders were, on average, 1.5 years older than responders and more often had a history of diabetes mellitus and malignancies. Knowing the impact of age and comorbidities, our prevalence estimates could therefore be an underestimation of the true rate of unrecognized chronic diseases.

\section{Conclusions}

Unrecognized chronic diseases might be detected in community-dwelling frail elderly using a simpleto-implement, near-home screening strategy. However, whether optimizing treatment of new diagnoses in this fragile population with multimorbidities and polypharmacy improves quality of life and reduces morbidity and mortality remains to be proven.

The authors thank the participating patients, primary care physicians, their assistants, and the personnel from Saltro laboratory (Utrecht, The Netherlands). The authors also thank Arif Nugroho Soenardi (cardiologist), Clemens G. K. M. Fauser (cardiologist), Marcel J. Landman (cardiologist), and Harm Jan Huidekoper (pulmonologist) for their contributions to the expert panel.

\section{References}

1. Landahl S, Steen B, Svanborg A. Dyspnea in 70year-old people. Acta Med Scand 1980;207:225-30.

2. Mulrow CD, Lucey CR, Farnett LE. Discriminating causes of dyspnea through clinical examination. J Gen Intern Med 1993;8:383-92.

3. van Mourik Y, Rutten FH, Moons KG, Bertens LC, Hoes AW, Reitsma JB. Prevalence and underlying causes of dyspnoea in older people: a systematic review. Age Ageing 2014;43:319-26.

4. Mosterd A, Hoes AW, de Bruyne MC et al. Prevalence of heart failure and left ventricular dysfunction 
in the general population; The Rotterdam Study. Eur Heart J 1999;20:447-55.

5. van Durme YM, Verhamme KM, Stijnen T, et al. Prevalence, incidence, and lifetime risk for the development of COPD in the elderly: the Rotterdam study. Chest 2009;135:368-77.

6. McCullough PA, Hollander JE, Nowak RM, et al ; BNP Multinational Study Investigators. Uncovering heart failure in patients with a history of pulmonary disease: rationale for the early use of B-type natriuretic peptide in the emergency department. Acad Emerg Med 2003;10:198-204.

7. Rutten FH, Cramer MJ, Grobbee DE, et al. Unrecognized heart failure in elderly patients with stable chronic obstructive pulmonary disease. Eur Heart J 2005;26:1887-94.

8. Dickstein K, Cohen-Solal A, Filippatos G, et al ; ESC Committee for Practice Guidelines. ESC guidelines for the diagnosis and treatment of acute and chronic heart failure 2008: the Task Force for the diagnosis and treatment of acute and chronic heart failure 2008 of the European Society of Cardiology. Developed in collaboration with the Heart Failure Association of the ESC (HFA) and endorsed by the European Society of Intensive Care Medicine (ESICM). Eur J Heart Fail 2008;10:933-89.

9. Hogg K, Swedberg K, McMurray J. Heart failure with preserved left ventricular systolic function; epidemiology, clinical characteristics, and prognosis. J Am Coll Cardiol 2004;43:317-27.

10. Rutten FH, Cramer MJ, Lammers JW, Grobbee DE, Hoes AW. Heart failure and chronic obstructive pulmonary disease: an ignored combination? Eur J Heart Fail 2006;8:706-11.

11. Bednarek M, Maciejewski J, Wozniak M, Kuca P, Zielinski J. Prevalence, severity and underdiagnosis of COPD in the primary care setting. Thorax 2008; 63:402-7.

12. Geijer RM, Sachs AP, Hoes AW, Salomé PL, Lammers JW, Verheij TJ. Prevalence of undetected persistent airflow obstruction in male smokers 40-65 years old. Fam Pract 2005;22:485-9.

13. Wheeldon NM, MacDonald TM, Flucker CJ, McKendrick AD, McDevitt DG, Struthers AD. Echocardiography in chronic heart failure in the community. Q J Med 1993;86:17-23.

14. van Mourik Y, Moons KG, Bertens LC, Reitsma JB, Hoes AW, Rutten FH. Triage of frail elderly with reduced exercise tolerance in primary care (TREE). A clustered randomized diagnostic study. BMC Public Health 2012;12:385.

15. Clegg A, Young J, Iliffe S, Rikkert MO, Rockwood K. Frailty in elderly people. Lancet 2013;381: 752-62.

16. Morley JE, Vellas B, van Kan GA, et al. Frailty consensus: a call to action. J Am Med Dir Assoc 2013;14:392-7.
17. Jorgensen T, Johansson S, Kennerfalk A, Wallander MA, Svärdsudd K. Prescription drug use, diagnoses, and healthcare utilization among the elderly. Ann Pharmacother 2001;35:1004-9.

18. Fletcher CM, Elmes PC, Fairbairn AS, Wood CH. The significance of respiratory symptoms and the diagnosis of chronic bronchitis in a working population. Br Med J 1959;2:257-66.

19. Bailie GR, Uhlig K, Levey AS. Clinical practice guidelines in nephrology: evaluation, classification, and stratification of chronic kidney disease. Pharmacotherapy 2005;25:491-502.

20. Blackburn H, Keys A, Simonson E, Rautaharju P, Punsar S. The electrocardiogram in population studies. A classification system. Circulation 1960;21: $1160-75$.

21. Rose GA, Blackburn H. Cardiovascular survey methods. Monogr Ser World Health Organ 1968;56:1188.

22. Smeele IJM, van Weel C, van Schayck CP et al. [Practice guideline 'COPD' (second revision) from the Dutch College of General Practitioners]. Huisarts Wet 2007;50:362-79.

23. Rutten FH, Moons KG, Cramer MJ, et al. Recognising heart failure in elderly patients with stable chronic obstructive pulmonary disease in primary care: cross sectional diagnostic study. BMJ 2005;331: 1379.

24. Moons KG, Grobbee DE. When should we remain blind and when should our eyes remain open in diagnostic studies? J Clin Epidemiol 2002;55:633-6.

25. McMurray JJ, Adamopoulos S, Anker SD, et al. ESC Guidelines for the diagnosis and treatment of acute and chronic heart failure 2012: The Task Force for the Diagnosis and Treatment of Acute and Chronic Heart Failure 2012 of the European Society of Cardiology. Developed in collaboration with the Heart Failure Association (HFA) of the ESC. Eur Heart J 2012;33:1787-847.

26. Rabe KF, Hurd S, Anzueto A, et al; Global Initiative for Chronic Obstructive Lung Disease. Global strategy for the diagnosis, management, and prevention of chronic obstructive pulmonary disease: GOLD executive summary. Am J Respir Crit Care Med 2007;176:532-55.

27. Geijer RM, Smeele IJ, Goudswaard AN. [Summary of the practice guideline 'Asthma in adults' (second revision) from the Dutch College of General Practitioners]. Ned Tijdschr Geneeskd 2008; 152:1146-50.

28. Brown L, Cai T, DasGupta A. Interval estimation for a binomial proportion. Stat Science 2001;16: 101-3.

29. Pedersen F, Mehlsen J, Raymond I, Atar D, Skjoldborg US, Hildebrandt PR. Evaluation of dyspnoea in a sample of elderly subjects recruited from general practice. Int J Clin Pract 2007;61:1481-91. 
30. Rutten FH, Cramer MJ, Paulus WJ. [Heart failure with preserved ejection fraction: diastolic heart failure]. Ned Tijdschr Geneeskd 2012;156:A5315.

31. Nielsen LS, Svanegaard J, Wiggers P, Egeblad H. The yield of a diagnostic hospital dyspnoea clinic for the primary health care section. J Intern Med 2001;250:422-8.

32. Nielsen LS, Svanegaard J, Klitgaard NA, Egeblad H. $\mathrm{N}$-terminal pro-brain natriuretic peptide for discriminating between cardiac and non-cardiac dyspnoea. Eur J Heart Fail 2004;6:63-70.

33. Nagueh SF, Appleton CP, Gillebert TC, et al. Recommendations for the evaluation of left ventricular diastolic function by echocardiography. Eur J Echocardiogr 2009;10:165-93.

34. Paulus WJ, Tschöpe C, Sanderson JE, et al. How to diagnose diastolic heart failure: a consensus statement on the diagnosis of heart failure with normal left ventricular ejection fraction by the Heart Failure and Echocardiography Associations of the European Society of Cardiology. Eur Heart J 2007;28:2539-50.

35. Brenner S, Güder G, Berliner D, et al. Airway obstruction in systolic heart failure-COPD or congestion? Int J Cardiol 2013;168:1910-6.

36. Güder G, Rutten FH, Brenner S, et al. The impact of heart failure on the classification of COPD severity. J Card Fail 2012;18:637-44. 


\section{Appendix 1}

Questionnaire on Dyspnea and Exercise Tolerance

Table 3

Medical Research Council Dyspnea Scale*†

Responses (\%)

0. No breathlessness

1. Not troubled by breathlessness except on strenuous exercise.

2. Short of breath when hurrying on the level or walking up a slight hill.

3. Walks slower than most people on the level, stops after a mile or so, or stops after 15

minutes walking at own pace.

4. Stops for breath after walking about 100 yards or after a few minutes on level ground.

5. Too breathless to leave the house or breathless when dressing or undressing.

Questionnaire to evaluate exercise tolerance

Yes Responses (\%)

Do you have a reduced exercise tolerance compared with others of the same age?

Do you feel more tired than others of the same age?

Do you feel you need more recovery time after exercise than others of the same age?

Do you feel your heart is pounding or feel palpitations or feel agitated during activities such as walking, gardening, or housework?

Response to the above questions were all negative

${ }^{*}$ Medical Research Council Dyspnea Scale, adapted from Fletcher et al. ${ }^{18}$

${ }^{\dagger}$ One instance of missing data.

${ }^{\ddagger}$ Questions translated from Dutch to English.

${ }^{\$}$ Two instances of missing data.

"Three instances of missing data. 